\title{
Conversations between architects and engineers
}

\author{
Marina Ferreira Borges ${ }^{1}$ \\ ${ }^{1}$ Federal University of Minas Gerais \\ ${ }^{1}$ marinafborges@gmail.com
}

The structural education in architectural schools emphasize that the dialogue between professionals is what should be raised as the point of connection between the conception of the structural morphology to be carried out by the architect and its validation and construction by the structural engineer. However, is this dialogue occurring? The proposal of this work is to study the conversational model proposed by Paul Pangaro (2009), based on Gordon Pask's Conversation Theory (1976a), and investigate if in fact a dialogic process between architectural design and structures education in architectural schools occurs, or if there exist the possibility of proposing a new conversational model, promoting transdisciplinary participation and collaboration procedures.Please write your abstract here by clicking this paragraph.

Keywords: Architectural Design Teaching, Structural Education, Conversation Theory

\section{INTRODUCTION}

Structural education is a key piece for that architectural students think about the relations between form, materiality and tectonics, since they aid in the reasoning of physical procedures for design, leading to a point of convergence between the disciplines of architectural design and structural engineering, whose lack of organicity only accentuates the fragmentation between design and construction. Structural education in architecture is not an end as in civil engineering courses that form professionals who develop structural calculations; should be a means for students to think about the tectonics of the form. The fragmentation between the disciplines of architectural design and structural engineering corroborates to an atectonic design thinking, favoring the simplistic application of technique and the generation of fashion images (FRAMPTON, 1995).
For decades, structural education in architectural schools has trained architects to the routine of structural engineers, in which there is no critical, reflexive and dialogical knowledge (SANTOS, KAPP, 2014). With disciplines focused mainly on quantitative aspects, they are too abstract, and do not offer to architectural student's adequate tools to appropriate itself to the relationship of material behavior to design a structural system. Thus, they fail to develop a structural reasoning from an analytical understanding of the various possible solutions to a design problem.

However, the teaching plans of structures disciplines offered in the architectural schools emphasize that the dialogue between professionals is what should be raised as the point of connection between the conception of the structural form to be carried out by the architect and its validation and construction by the structural engineer. But in teaching prac- 
tice is this desirable dialogue between architectural design disciplines and structural education is effectively taking place?

To realize this analysis, we propose as methodology use the conversational model of Pangaro (2009) based on the concepts developed by Gordon Pask's Theory of Conversation (1976a). Thus, will be organized a conversational model adapted to analyze the relationship between architectural design teaching and structural education will be organized, in order to identify the existing problems in the current model. With this, it will be possible to propose a conversational model among these disciplines that effectively allows a dialogic practice of design, instrumenting the architects to elaborate new project systems that propitiate a practice of collective construction of knowledge through participatory and collaborative processes, in which architecture becomes a knowledge, not an autonomous discipline (MONTANER, 2017).

\section{CONVERSATION THEORY}

Conversational Theory was developed by Gordon Pask (1976a) and originated from a cybernetic assembly in which the fundamental idea is that learning occurs through conversations about the subject matter of the discipline, making knowledge explicit. Pask defines conversation as "an intersection between two second order systems in which humans, machines and environments may be engaged in collaborative information exchange." Second-order cybernetics applied to the design places it as a conversation in which participants must learn together. According to Pask (1980), the Theory of Conversation is used to illustrate an argument in favor of reflexive and relativistic theories in cybernetics and systems studies. Language in the Theory of Conversation is fundamental, in that through a means of processing, has as its property the ability to question, command, respond, obey and explain a certain goal.

Dubberly and Pangaro (2009) use Gordon Pask's cybernetic models of conversation theory because they are based on an in-depth study of the interac- tion between human-human and human-machine, in which it is believed that in conversation it is only possible to learn new concepts, share and evolve knowledge, and, confirm agreement. In conversation the output of one learning system becomes the input to another.

In conversation systems, based on cybernetic theory, humans, machines and environments can be engaged in collaborative information exchange. For Dubberly and Pangaro (2009), the conversation process occurs when its participants perform the following tasks:

1. Open a channel by sending an initial message of common interest;

2. Commit to engage with a symmetrical relationship between participants;

3. Construct meaning, in which the basis of the conversation must be the sharing of contexts, with common language and same social norms;

4. Evolve, since the conversation affects both participants, in which changes brought about by the conversations have lasting value;

5. Converge on agreement through common goals;

6. Act or transact, developing cooperative relationships;

The Conversion Theory applied to teaching practices requires that the methodology developed have a cyclicality that allows the student to reconstruct a concept and a consistency, allowing all the approached topics can be identified separately (PASK, 1976b), opening new processes of conversation. In the autonomous conversation model by Pangaro (2009), as shown in Figure 1, the Participant $A$ is the one who initiates the process of collaboration through the conversation, defining the initial goals according to his point of view, articulating the logic of conducting the conversation considering that new goals or new opportunities can emerge during the process. The Participant A has access to a learning structure but is ignorant of some topics. The Par- 
ticipant $B$ should have the answers to the questions of Participant A providing appropriated demonstrations (PASK, 1976b). The conversation begins only if one of the participants have a goal, specific or general, articulated or without form.

Thus, Pangaro (2009) systematizes what would be a conversational model and establishes some requirements for its organization:

1. Context: moment, situation, place and/or shared history;

2. Language: initial shared means for conveying meaning;

3. Agreement: shared understanding of concepts, intent, values that may lead to an action;

4. Exchange: availability for interaction, result of a shared language and a context conducive to interaction that can build an agreement;

5. Action or (Trans)action: cooperative conversation, circular and recursive.

\section{ANALYSIS OF CURRENT TEACHING PRAC- TICE}

In structures disciplines currently offered in architectural school, what exists is a technical communication. For Pask (apud PANGARO, 2017) the difference between communication and conversation is that for the dialogue to occur, something must be transformed for one or more participants, be it the understanding of the subject, concepts, intentions or values. If this transformation does not occur, what happened was a mere exchange of messages.

The current model of structural education is fragmented into disciplines that follow a similar civil engineering education, having disciplines of theoretical foundation (introduction to structural systems), intermediate knowledge (structural analysis and resistance of materials) and specific advanced knowledge (concrete, steel and wood). All disciplines have as bias the structural analysis by the analytical method, that is, using mathematical equations. Experimental methods, focused on the development of physi- cal models, and computational methods that allow a better visualization of the physical behavior of the models are not used. In this way, students are only instrumented with an abstract mathematical language that is difficult to apply to architectural design. In this way, is the mathematical and abstract language used for teaching structures in architectural schools enough for the establishment of a conversational practice?

In architectural teaching, design disciplines wish to learn about structures for definitions of spatiality, morphology, and construction materiality. The role of teaching structures is a cooperative action with the dialogue to be established. Thus, in this dialogue, architectural design teaching is Participant A (which initiates the conversation with an action) and structural education is Participant $B$ (which reacts to this action with a transaction).

The objective of this dialogue should be to provide the architect with structural knowledge that allows flexibility in structural parameters in harmony with spatial articulation. The structure in a tectonic design conception is not an autonomous object that must suit the space or vice versa. The architectural design teaching is (or should be) the driver of the conversation between agents, promoting the opening of common channels of conversation. In the current teaching model there is no formalized environment for the conversation with teaching of structures to take place.

In this way, we will first analyze current teaching practice through the bias of the conversational model, verifying if there is a conversation between architectural design teaching and structural education within the context of each discipline:

\section{Participant A: Architectural Design Teach- ing}

1. Context: architectural design disciplines;

2. Language: manual or digital representation methods of architectural design;

3. Agreement: launch of the structure according to pre-sizing criteria; 
4. Exchange: when it occurs, happens through the analysis of examples and counterexamples of structural solutions of analogous works. It may also occur consulting the specific bibliography of structural knowledge directed to the learning of architects;

5. Action or (Trans)action: practically does not occur. It depends on the individual willingness of design teachers and students to seek some contact with the teachers of structures disciplines.

\section{Participant B: Structural Education}

1. Context: disciplines of structures;

2. Language: mathematics through analytical method;

3. Agreement: according to the subjects of disciplines, only the basic concepts of the contents are offered in such a way that the architects can carry out a structural pre-dimensioning and dialogue with structural engineers in professional practice;

4. Exchange: the inadequacy of the application of language to design development does not allow the exchange;

5. (Trans)action: practically nonexistent since the exchanges are made difficult by the language used;

In the current model, there is no possibility of feedback, and a process of linear causality is created. According to Dubberly and Pangaro (2015a), this linear process does not allow the iteration, which would be the correction of the error, and the convergence of objectives among the participating agents, limiting design to simplified feedbacks. In this way, for the proposition of a conversational model between the architectural design teaching and structural education, it is important that there is a context that allows the possibility of multiple feedbacks, promoting cir-

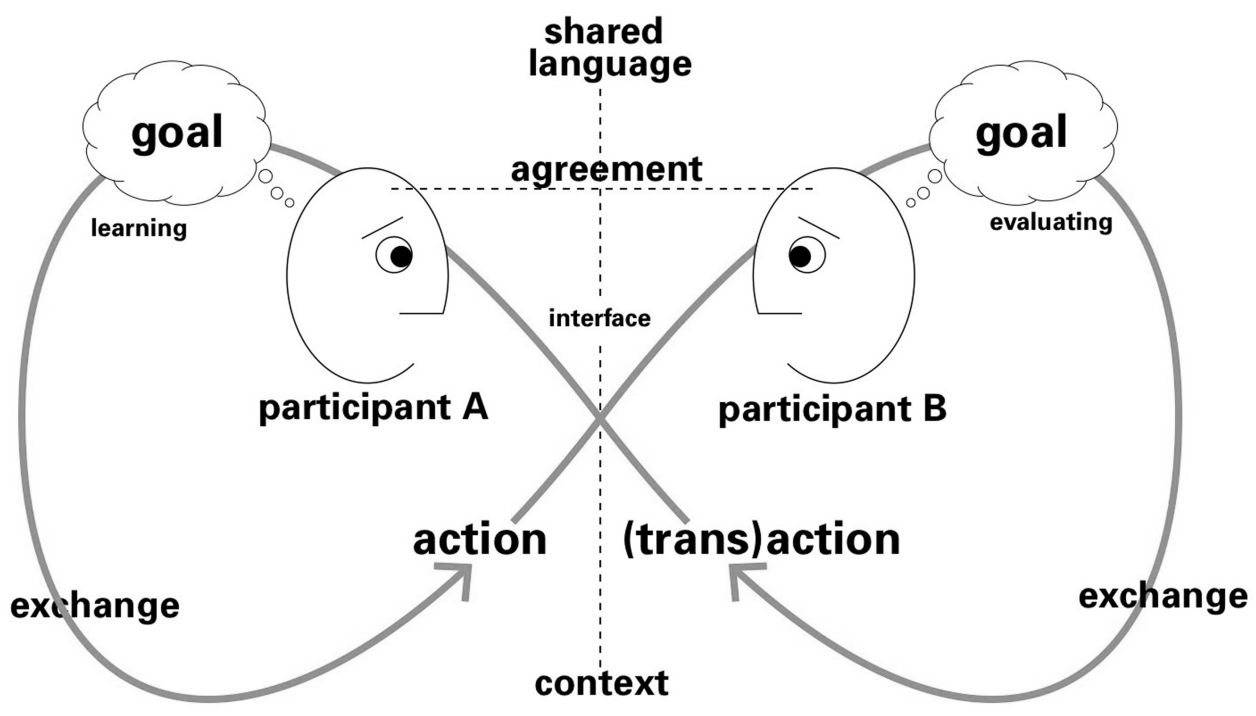

Figure 1

Simplified view of Pask's view of conversation. Pangaro, 2017. 
cularity and recursion. For this, it is fundamental that the interaction of Participant $B$ in the context of Participant $A$, developing a common language, with explicit objectives, in a context that facilitates the exchanges, in which these will serve as the basis for a joint action and for the creation of new values.

\section{PROPOSAL OF A CONVERSATIONAL MODEL}

Cybernetics studies how systems organize themselves, dealing with how they communicate internally and with other systems, which stimulates collaborative transdisciplinary thinking. For Von Foerster (apud DUBBERLY, PANGARO, 2015b, p.5), "one can and should try to communicate beyond the boundaries, and often the abysses, that separate the various sciences."

Some attempts to promote this integration have been developed to improve the dialogue between architectural design teaching and structural education. As can be seen in III Eneeea, some Brazilian universities focus on language change (experimental methods with the use of physical models or experiments in experimental beds), others involving new participants (engineering professors present in the design disciplines), or still, in the proposition of a new conversational model.

However, these propositions are focused on technical communication, not presenting more reflections regarding the changes of the architecture itself and its contemporary condition. For Montaner (2016), contemporary architecture has a contextualist and complex synthesis character, in which a new pragmatism is reformulated through practical tools of knowledge, analysis and design. According to him, the diagrammatic practices and the digital tools propitiate the development of an architectural theory related to an interactive pragmatism. Pangaro (2011) believes that design development should be more concerned with the design process than with the shape of objects, and that without the creation of a new language, innovation is limited to improvements in existing processes. But, how to develop a new language?

The proposal of a new conversational model between the architectural design teaching and structural education seeks to promote a common language among the participants, so that it is possible for the exchanges to be effectively carried out. For this, it is fundamental that Participant B promote its (trans) action within the same environment of design teaching (Participant A). Participant $B$ can be machine (use of structural analysis software) or human (teacher of structures disciplines). In this way the proposed conversations are about promoting humanmachine interaction, or human-machine-human interaction.

\section{Conversation human-machine}

In the first hypothesis, which we will call the Conversational Model Type 1 (focusing on human-machine conversation), the proposal is to develop a teaching model in which students use structural analysis software to develop performance-based design methodologies with focus in optimization, generation or computational form-finding) in the existing design disciplines. This model, as elucidated in Table 1, consists of involving Participant B in the conversation (structural analysis software) through humanmachine interaction. This conversational model produces the following interactions:

In this model, Participant $A$ are the architectural design teacher (A.1) and students (A.2), and Participant $B$ is the structural analysis software (B.1). The design teacher establishes the dialogue with the software in two moments: in the first, in the selection and verification of the possibility of feedbacks according to the objective; and in the second, directing the students to interact with the software in the developed process. The conversation takes place between design teachers, students, and structural analysis software. The purpose of human-machine conversation is to broaden the possibilities for conversation.

Interaction with computers serves to cooperate in making decisions in complex situations. In advanced design environments, what for Oxman 


\begin{tabular}{|c|c|c|c|}
\hline & Participant $\boldsymbol{A}$ - actic & & Participant B - (trans) action \\
\hline Conversation & Human $(A .1)$ & Human $(A .2)$ & Machine (B.1) \\
\hline Human (A.1) & $\begin{array}{l}\text { between } \\
\text { architectural design } \\
\text { teachers }\end{array}$ & $\begin{array}{l}\text { students - architectural } \\
\text { design teacher }\end{array}$ & $\begin{array}{l}\text { structural analysis software - } \\
\text { architectural design teachers }\end{array}$ \\
\hline Human $(A .2)$ & $\begin{array}{l}\text { architectural design } \\
\text { teacher - students }\end{array}$ & between students & structural analysis software - students \\
\hline Machine $(B .1)$ & $\begin{array}{l}\text { architectural design } \\
\text { teacher - structural } \\
\text { analysis software }\end{array}$ & $\begin{array}{l}\text { students - structural } \\
\text { analysis software }\end{array}$ & Computacional iteraction \\
\hline
\end{tabular}

Table 1

Conversacional

Model Type 1.

Prepared by the author.
(2008) would be the performance-based design, using human-machine interaction and iteration between multiple agents, it is possible to create a conversation process with multiple feedbacks and recursion. This process would have the potential to transform the relationships between architects and engineers, where through a common language provided by the digital medium, values would be explicit and both would share the same goal.

Oxman (2012) defines performance as the ability to act directly on the physical properties of design and can be extended to include qualitative aspects as spatial factors in technical simulations. For Kolarevic (2005), the concept of performance goes far beyond aesthetic, functional and technical aspects, and can be extended to a financial, cultural, spatial and social dimension. The understanding of performance as a process demands a revision of the understanding of the "built body" as a "static body", suggesting the etymological idea of the formation of the architectural object through movement.

In addition to the dialogue between architectural design and structures, the performance-based digital design includes the computer as part of the process, a third participant involved in the conversation. Incorporating technology as a conversation interface tool provides participants with a shared language for a cooperative dialogic process, facilitating the development of an interactive, iterative, circular, and recursive process. For Oxman and Oxman (2010), the digital cooperative process dilutes the questions of authorship of form, through investigative and experimental processes, reversing the way of thinking form, force and structure.

In this way, based on the human-machine conversation applied to teaching, it was proposed the use of structural analysis software's in design disciplines. Thus, we have the following structure for the development of the Conversational Model Type1:

1. Context: architectural design disciplines;

2. Language: use of simplified structural analysis software for structural form-finding integrated to theoretical classes of material properties;

3. Agreement: learning of structural analysis software to aid in the preliminary structural sizing of the proposed structural typology;

4. Exchange: the software provides the preliminary structural sizing through the amount of material required;

5. Action or (Trans)action: recursion in the preliminary sizing and in the choice of materials during the development of the architectural design;

In this model, what is observed is that students who 
already have intermediate and advanced knowledge (both of design and structures) can engage in the conversation model. This is because they can understand the objectives, the proposed language and in this way use the software transaction for application in the design process. However, what is perceived in this model is that the simplification of the language used does not allow the engagement for recursion and the engagement with other conversations, being only an efficient tool for the students to explore the materiality of the object.

\section{Conversation human-machine-human}

In a second hypothesis for the construction of the model, due to its limitations identified in Type 1, the demands of knowledge extrapolate the humanmachine conversation and it is necessary to include a new Participant $B$, who would be a structural engineering teacher. This can be introduced as a new element, extending the human-machine conversation to a human-machine-human conversation, opening new channels of conversations that need to be worked on. In this model, which will be identified as Conversational Model Type 2, several conversations can occur simultaneously as shown in Table 2 , which would require that the design teacher explain to all participants the goal and values involved, with an agreement and an engagement of all in order to avoid noise, and consequently, conflicts of interest between the participants.

According to Pask (1980), a person can simultaneously have the perspective of more than one participant, unifying the internal conversation. When adopting different roles, this participant should consider the merits of the various hypotheses that may arise from the other participants. In this model the Participant $A$ in the figure of the design teacher (A.1), would be the participant that performs this function. If there is no agreement and engagement with Participant $B$ in the structural engineering teacher figure (B.2), the entire process may lead to a conflicting transaction, or even make it unfeasible. In this proposition, several conversations may occur:
The proposal to create the Conversational Model Type 2, considering all the complexity involved and the multiple interactions provided, is not to create a closed model, but to create a system with explicit subjectivities, values and responsibilities, allowing all participants to create. Conversation is necessary to converge on shared goals, and so reorder the situation in order to act together. In this way, the conversation between people is fundamental for understanding the principles of duality, complementarity and conservation. In this way, there can be no loss of concepts in the development of a single environment for the two disciplines (design and structures). For Pask (1980), the principle of conserving the information to be transferred in the conversation through language and means is what maintains the coherence of the system. In this way, the proposition of a Conversational Model Type 2 for the synthesis of all conversations that would occur internally, encompasses the following definitions:

1. Context: hybrid disciplines of architectural and structural design;

2. Language: learning of structural analysis software integrated to theoretical classes of structural design in its quantitative and qualitative dimensions;

3. Agreement: learning of concepts and application in the software for iteration with the computational model;

4. Exchange: development of an iterative process in which the participants have the software evaluations as interface for the dialogue;

5. Action or (Trans)action: recursion in the development of architectural design. The participation of the structural engineering teacher is required for the sophistication of the iteration. Architects and engineers develop a collaborative relationship;

In order to promote a circular and recursive process in a complex model like Type 2, the pedagogical structure of the proposed disciplines can be divided into four moments based on Pangaro (2011), being all it- 


\begin{tabular}{|c|c|c|c|c|}
\hline \multirow[b]{2}{*}{ Conversation } & \multicolumn{2}{|l|}{ Participant $\boldsymbol{A}$ - action } & \multicolumn{2}{|c|}{ Participant B - (trans) action } \\
\hline & Human $(A .1)$ & Human $(A .2)$ & Machine (B.1) & Human (B.2) \\
\hline Human $(A .1)$ & $\begin{array}{l}\text { between } \\
\text { architectural design } \\
\text { teachers }\end{array}$ & $\begin{array}{l}\text { students - } \\
\text { architectural } \\
\text { design teacher }\end{array}$ & $\begin{array}{l}\text { structural analysis } \\
\text { software - } \\
\text { architectural } \\
\text { design teachers }\end{array}$ & $\begin{array}{l}\text { structural engineering } \\
\text { teacher- architectural } \\
\text { design teachers }\end{array}$ \\
\hline Human (A.2) & $\begin{array}{l}\text { architectural design } \\
\text { teacher - students }\end{array}$ & between students & $\begin{array}{l}\text { structural analysis } \\
\text { software - } \\
\text { students }\end{array}$ & $\begin{array}{l}\text { structural engineering } \\
\text { teacher-students }\end{array}$ \\
\hline Machine (B.1) & $\begin{array}{l}\text { architectural design } \\
\text { teacher - structural } \\
\text { analysis software }\end{array}$ & $\begin{array}{l}\text { students - } \\
\text { structural analysis } \\
\text { software }\end{array}$ & $\begin{array}{l}\text { computacional } \\
\text { iteraction }\end{array}$ & $\begin{array}{l}\text { structural engineering } \\
\text { teachers - structural } \\
\text { analysis software }\end{array}$ \\
\hline Human (B.2) & $\begin{array}{l}\text { architectural design } \\
\text { teacher - structural } \\
\text { engineering } \\
\text { teachers }\end{array}$ & $\begin{array}{l}\text { students - } \\
\text { structural } \\
\text { engineering } \\
\text { teachers }\end{array}$ & $\begin{array}{l}\text { validation of } \\
\text { results }\end{array}$ & $\begin{array}{l}\text { conversation between } \\
\text { structural engineering } \\
\text { teachers }\end{array}$ \\
\hline
\end{tabular}

Table 2

Conversational

Model Type 2.

Prepared by the author. erative and recursive:

A. Conversation to Agree on Goals: moment that the objectives must be explained and agreed upon until they are brought to engagement;

B. Conversation to Design the Designing: moment of identification of irreplaceable knowledge for the design of a new space of possibilities;

C. Conversation to Create New Language: as a new space of possibilities evolves, a new language is shaped and defined;

D. Conversation to Agree on Means: agreement on the action plan for the development of products using the proposed conversational model.

Hybrid disciplines have as a proposal to open dialogues, not eliminating the possibility of maintaining the current disciplines of structures, on the contrary, stimulate students to look for these theoretical tools to better understand how to use the resources of analysis and iteration provided by structural analysis software's. The software visual resources allow the visualization of the behavior of the structures, leading to a recognition of the concepts learned through analytical mathematical models, which, because they are too abstract, are generally not well understood.

What was noticed in the development of Conversational Model Type 2 is that the difference between students with basic knowledge of structures and students with intermediate and advanced knowledge is not perceived, being that all engage in the development of the iterative process and require the participation of a structural engineering teacher in the process. This conversation can even extrapolate the edges of the discipline itself, enabling and encouraging students to seek new knowledge with other structural engineering teachers or even with other construction workers (designers, industry and construction workers).

Students with advanced knowledge of both design and structures, engage in dialogue that overflows the discipline. These students seek the theoretical knowledge offered in the traditional disciplines of structures (some return to attend classes in 
disciplines such as resistance of materials and structural analysis), seek dialogue with other structural engineer teachers, seek other structural analysis software's, other professionals in the field and even engage in a critical dialogue with the construction industry.

\section{CONCLUSION}

The modern division of labor has led architects and engineers to develop a collaborative relationship through help or support. That is, the architect develops a project and the engineer helps or assists him with his work, not acting jointly in his development. The change of relationship in the sense of developing a cooperative work redefines the positions of professionals and re-approximate the work of both, where the action takes place jointly for the same purpose.

The pedagogical proposal to develop conversational models for teaching design and structures goes through what Montaner (2017) purposes for a practice towards an architecture of action. For Dubberly and Pangaro (2015a), the conversation for action promotes an ethical (in agreement with goals), cooperative (in agreement with means), innovative (creating a new language) and responsible (creating a new process).

According to Dubberly and Pangaro (2015a), knowledge of vocabulary and grammar is not a prerequisite but provides a more fertile ground for the emergence of poetry, and of delight. By designing interactive environments as computational extensions of human agency or new social discourses to govern social change, second-order design facilitates the emergence of conditions in which others can design, creating conditions in which conversations can emerge, thereby increasing the number of options open to all.

In order for structural education to be part of a conversation within the design disciplines, it is necessary that the architectural design teaching is also open to substitution of a typological model, with a correctness of the linear form, for a topological performance model, in which the architect does not have control of the designed object, but rather of the process, allowing architecture to emerge from participation and emergence between a variety of agents. The digital tools of structural analysis provide a set of iterativity between the parameters used to conceive the space and its possibilities of materialization through processes of optimization, generation or a structural form-finding. In this case, the computer acts as a cybernetic instrument that responds to the parameters established by the students for the design of the structural system instructing and being instructed by it, in a recursive process that can add as many agents as necessary. In this process unexpected results can emerge, not foreseen initially, creating novelty for both participants.

The creation of collaborative design processes in which knowledge is built collectively through the participation of other agents leads to a paradigm shift. Established conversations can transform individuals and organizations by changing values and modes of arrangement, and conversation initiated in teaching can be replicated in professional practice. For Pangaro (2017), when a conversation begins, it never ends. In this way, we believe that the conversation initiated in the teaching environment has the capacity to transform professional practice, thus modifying the relationships between civil construction agents (architects, engineers, workers and users) and their forms of participation through the emergence of dialogical practices, in which the discussion is oriented by the object that connects them or can connect.

\section{REFERENCES}

Dubberly, $\mathrm{H}$ and Pangaro, P 2009, 'What is Conversation? How can we design for effective conversation?', Interactions Magazine, 16, pp. 1-8

Dubberly, $\mathrm{H}$ and Pangaro, P 2015a, 'Cybernetics and Design: Conversations for Action', Cybernetics and Human Knowing, 22(2-3), pp. 73-82

Dubberly, $\mathrm{H}$ and Pangaro, P 2015b, 'Cybernetics and Design: Conversations for Action', in Blauvelt, A, Castillo, G and Choi, E (eds) 2015b, Hippie modernism: The struggle for utopia, Walker Art Center, Minneapolis, pp. 126-141 
Frampton, K 1995, Studies in Tectonic Culture: The Poetics of Construction in Nineteenth and Twentieth Century Architecture, The MIT Press, Cambridge

Kolarevic, B 2005, Performative Architecture Beyond Instrumentality, Spon, NewYork

Montaner, JM 2016, A condição contemporânea da arquitetura, Gustavo Gili, São Paulo

Montaner, JM 2017, Do diagrama às experiências, rumo à uma arquitetura de ação, Gustavo Gili, São Paulo

Oxman, R 2008, 'Performance-based design: current practices and research issues', International Journal of Architectural Computing, 6(1), pp. 1-17

Oxman, R 2012, 'Informed Tectonics in Material based Design', Design Studies, 33(5), pp. 427-455

Oxman, R and Oxman, R 2010, 'The New Structuralism: design, engineering, and architectural technologies', Architectural Design, 80(4), pp. 15-23

Pangaro, P 2009 'How Can I Put That? Applying Cybernetics to "Conversational Media"', American Society for Cybernetics, Washington

Pangaro, P 2011 'Design for Conversations \& Conversations for Design', coThinkTank, Berlin

Pangaro, P 2017, 'Questions for Conversation Theory or Conversation Theory in One Hour', Kybernetes, 46(9), pp. 1578-1587

Pask, G 1976a, Conversation Theory: applications in education and epistemology, Elsevier, Amsterdam

Pask, G 1976b, 'Conversational techniques in the study and practice of education', British Journal of Educational Psychology, 46(1), pp. 12-25

Pask, G 1980 'Developments in Conversation Theory: actual and potential applications', International Congress on Applied Systems Research and Cybernetics, Acapulco

Santos, R and Kapp, S 2014 'Articulação como Resistência', III ENANPARQ 2014, São Paulo

Zumthor, P 2007, Performance, recepção, leitura, Cosac Naify, São Paulo 